\title{
Experiential and Real-World Learning for Teachers in the Billion Oyster Project and Curriculum and Community Enterprise (BOP-CCERS) for the Restoration of New York Harbor with New York City Public Schools Program
}

\author{
Lauren B. Birney, ${ }^{1, *}$, Joyce Kong ${ }^{1}$, Brian R. Evans ${ }^{1}$, Samantha Ceritelli ${ }^{1} \&$ Macey Danker ${ }^{1}$ \\ ${ }^{1}$ School of Education, Pace University, 1 Pace Plaza, New York, NY 10038, USA \\ *Correspondence: School of Education, Pace University, 1 Pace Plaza, New York 10038, USA. Tel: 1-212-346-1323. \\ E-mail: LBirney@pace.edu
}

National Science Foundation Award Number DRL 1440869, DRL 1759006, DRL 1839656

Any findings, conclusions, or recommendations expressed in this material are those of the authors and other contributors and do not necessarily reflect the views of NSF.

Received: August 26, 2019

Accepted: September 14, 2019 Online Published: November 6, 2019

doi:10.5430/jct.v8n4p30

URL: https://doi.org/10.5430/jct.v8n4p30

\begin{abstract}
The Billion Oyster Project and Curriculum and Community Enterprise for the Restoration of New York Harbor with New York City Public Schools (BOP-CCERS) seeks to integrate harbor restoration activities with science teachers in order to provide their students with experiential learning through environmental impact in New York City with the vision that public school students in New York City can benefit from environmental science and experiential learning work through authentic research, data collection, and experimentation. The purpose is to engage science teachers with experiential learning opportunities in the New York Harbor that helps them create engaging lessons for their own students. It was found that teachers responded most positively to workshops that included hands-on activities, specifically the oyster restoration station trainings, classroom oyster tank setups and activities with scientists. Teachers reported that the BOP-CCERS program prepared them to support student learning of the program content and scientific research activities. Students who engage in real-world science are more likely to see the relevance of science and see themselves working toward a career pathway in STEM.
\end{abstract}

Keywords: professional development, experiential learning, project-based instruction, science curriculum, out-of-school science education, environmental restoration, environmental science, field experience, citizen science

\section{Introduction}

Experiential learning has the potential to enhance student educational experiences through engagement, improved attitudes, and higher success in the subject. Science experiential learning often happens in a science laboratory or in the field. It gives students the opportunity to see the real-world connections with the science classroom, and to also experience science in the way that scientists do. This can generate interest in science as a career and conduct science in a way that engages students through their own discoveries and applications of the science curriculum. Environmentally oriented STEM programs develop students' academic skills along with providing opportunities for college preparation, job training, building 21 st century skills while participating in community ecological restoration efforts. (Birney \& Cronin, 2018).

The Billion Oyster Project and Curriculum and Community Enterprise for the Restoration of New York Harbor with New York City Public Schools (BOP-CCERS), funded by the National Science Foundation (Award Number DRL 1440869, DRL 1759006 and DRL 1839656), seeks to integrated harbor restoration activities with science teachers in order to provide their students with experiential learning through environmental impact in New York City (Birney, 
McNamara, Evans, Woods, \& Hill, 2019). The vision for this project is that public school students in New York City can benefit from environmental science and experiential learning work through authentic research, data collection, and experimentation (Birney, Kong, Evans, Persaud, \& Danker, 2018). BOP-CCERS is both an education and a restoration initiative with the purpose of educating New York City public school students about their harbor, but also to restore the harbor for future generations.

The BOP-CCERS method is to use hands-on experiential learning centered around the New York Harbor with New York City public school science teachers in order to integrate experiential methods of teaching in their own science classrooms. Teachers learn about harbor restoration through university faculty, scientists, and other science professionals, and also engage with science in the field and New York harbor.

BOP-CCERS connects New York City schools with the extended classroom of New York Harbor. One of the fundamental challenges of teaching and learning outside of the classroom in the nation's largest and most urbanized system is access to the natural world. Pollution, securing permissions from private or public entities, and competition for use of limited natural space make it difficult for teachers to carry out inquiry and project-based instruction. (Janis, Birney, \& Newton, 2016). BOP-CCERS is a program of student education and teacher training leverages partnerships between university faculty, scientists, STEM professionals, cultural institutions, and community organizations. It provides opportunities for New York City public school teachers and students to actively participate in the planning, restoration, and monitoring of oyster reefs in New York Harbor.

\section{Theoretical Framework and Literature Review}

The theoretical framework for this study is grounded in Vygotsky's (1987) sociocultural theory, which is a social learning process collaboratively in the frame of a community of learners (Birney, Kong, Evans, Danker, \& Grieser, 2017). Teachers guide learning through community of practice (Cobb, 1994; Cobb \& Yackel, 1996). Teachers lead a community of practice through collaborative experiential learning in which students practice science as scientists.

Gunter and Reeves (2017) determined the most effective methods for educating teachers to integrate newer technologies into their curriculum, and found that students learn best when the process is hands-on, interactive, and authentic. In order for this integration of new technology to be effective, teachers must learn not only how to operate the new equipment and websites, but also how to integrate them into their curriculum to meet the shifting needs of their students. In this current study, there was an emphasis on teachers learning best and benefiting from professional development when this process is hands-on, interactive, and authentic, rather than through more formalized and less hands-on professional development approaches. The most significant results of this study found that an online professional development course using an authentic, integrated, subject-specific curriculum changed teachers' dispositions toward the worth of mobile learning. This type of teacher learning also empowered them to change their own instructional strategies to integrate mobile learning into their curriculum.

For many years, hands-on simulations have been used within the education system mostly to develop technical skills (Khaled, Gulikers, Biemans, \& Mulder, 2016). The goal of the study by Khaled et al. (2016) was to analyze how self-regulated learning (SRL), affects hands-on simulations, and the study showed that students and teachers use SRL and explained the strategies used. The results showed that both students and teachers used SRL behavior, but with room for improvement. For example, teachers used strategies such as modelling and scaffolding frequently but feedback was provided less often. Moreover, Martin and Bollinger (2018) explored engagement strategies using online learning with students, especially learner-to-instructor engagement. The subjects of the study were 150 students who completed a 38-item survey on learner-to-learner, learner-to-instructor, and learner-to-content engagement strategies. Learner-to-instructor engagement strategies seemed to be most valued among the three groups. Researchers found that rapport and collaboration between students and instructors in an interactive environment was significant. Additionally, Ho, Nakamori, Ho, and Lim (2016) investigated a blended learning model using a hands-on approach in which 117 teachers used a blended learning approach. Ho et al. (2016) compared knowledge, self-efficacy, and satisfaction to show that the blended learning group demonstrated a much higher level of knowledge. The authors did not find an increase in self-efficacy.

Kafyulilo (2010) examined the ways in which pre-service science and mathematics teachers can integrate technology into their teaching. It was found that practices can be effective in enhancing pre-service science and mathematics teachers' competencies, and the results showed that teachers who engaged in hands-on activities developed their technological and pedagogical content knowledge. Moreover, Fisher, Gerdes, Logue, Smith, and Zimmerman (1998) found that hands-on learning could enhance higher order thinking skills in science class. The authors examined learning in younger children, and observed an increase in higher order skills after use of hands-on activities along with 
enhanced attitude toward science.

While conducted in a Spanish classroom, Elliot (2016) used experiential learning to teach students about environmental science education. Her approach integrated science with the learning of the Spanish language through direct experience of environmental science. While some students resisted an experiential model of instruction (compared to traditional methods), the author found an attitudinal shift in the students including the amount of work students put in the class.

Hollis and Fulya (2016) used experiential learning in food science to enhance student communication, collaboration, critical thinking, and problem solving at the college level. The authors integrated real-world learning with food product development for the students. Students had the opportunity to collaborate with one another and compete for a prize at the end of the project. It was reported that students found this process to be beneficial for their future careers. Moreover, Stofer (2017) provided ideas to integrated citizen science with experiential learning through the development of an educators' toolkit.

\section{Methodology}

This study utilized a descriptive, qualitative, and observational approach toward investigation in order to examine teachers' learning of experiential methods of teaching in their science classrooms. Between 2015-2018, three cohorts of classroom teachers were observed throughout their participation in BOP-CCERS Teaching Fellowship activities including monthly seminars and periodic check-ins with BOP-CCERS faculty, scientists, and staff. Teachers were guided through the use of modeling experiential methodologies in teaching directly in the seminars and through demonstrations of harbor restoration curricula. Teachers had the opportunity to use an inquiry approach to learning in which faculty and scientists served as guides and facilitators. Thus, the classroom teachers in the project have access to an inquiry and project-based curriculum and receive ongoing support through year-long professional development opportunities, an online digital platform for data collection, and a network of support from industry STEM professionals, teacher veterans, and peer educators. The model of learning is based around inquiry and discovery methods that were explored by the teachers and could be used in their own instruction with their own students.

BOP-CCERS collaborators developed a project-based learning curriculum based on Bybee's 5E model (Note 1) to teach core STEM-C concepts to middle-school students through the restoration of oyster reefs in New York Harbor. Content themes for professional development workshops included: New York Geography, Marine biochemistry, food webs, invertebrate biology, experimental scenarios, field site scenarios, inquiry-based pedagogy and environmental justice. Lessons engage teachers and students in long term restoration ecology and environmental monitoring projects with STEM professionals and citizen scientists. The curriculum includes both in-school and out-of-school learning experiences along with an online platform for educators to share and develop lessons. Field trips to exhibits with partners of informal education facilities also helped to reinforce and extend both the educators' and students' understanding.

Ongoing professional development was led by veteran teachers and scientists so teachers have opportunities to examine best pedagogy practices along with experiential learning in the field. Teachers were expected to use their professional development experience to (1) inform their classroom instruction on harbor ecology; (2) lead their students to two or more field expeditions to an Oyster Research Station during the school year; and (3) to mentor students for the Annual Research Symposium where students gather to present their research. As part of the training, teachers learn how to identify organisms living in New York Harbor and how to monitor oyster growth. Teachers also learn how to monitor the health of New York Harbor by conducting water quality tests. Program staff also meet with teachers to inform and assist with setting up the Oyster Research Station at a suitable location near the school. Topics covered include: setting up and maintaining a classroom oyster tank, teaching and learning strategies during the field expedition with students, and safety protocols along with other logistics of planning a field experience for students to conduct scientific research.

Participants in the BOP-CCERS Fellowship receive training and materials to set up an Oyster Restoration Station in New York Harbor. As required by the program, teachers agree to visit the Oyster Restoration Station with students for oyster monitoring and field research activities.

\section{Results}

To date, BOP-CCERS programming has provided professional development, supplies, curricular support and authentic learning experiences for 78 middle schools, 127 teachers, 110 scientist volunteers and over 5000 students 
(Birney, McNamara, Sanders, Luintel, \& Penman, 2018). Qualitative observations collected from 2015 to 2018 of the first three years of the BOP-CCERS program implementation included: (1) teacher attendance and participation in professional development workshops; (2) teacher reflections on teacher learning and practice; (3) teacher reflections on student learning; and (4) teacher's opinions on continuing with implementation of the curriculum and classroom activities beyond their fellowship.

\subsection{Teacher Attendance and Participation}

Professional development for teachers consisted of monthly workshops taught by experts in the field along with scientists from Columbia University's Lamont-Doherty Earth Observatory and curriculum specialists from New York Harbor Foundation. Learning goals included developing deeper knowledge and appreciation of marine biology and New York Harbor restoration, implementing inquiry-based lessons from the BOP-CCERS curriculum, using technology and scientific equipment and the digital platform for data collection, using project-generated data to teach the BOP-CCERS curriculum, and developing knowledge of field research practices. The most attended sessions were: scientist workshops, oyster restoration field trainings, and River Project workshops. One teacher noted, "Measuring oysters and examining the health of the oysters in the oyster tank was new. We also used our field data from ORS expeditions to examine the growth and health of oysters, which I had never done before." Teachers received content area support from the scientists and best practices were shared and discussed among fellowship participants and BOP-CCERS curriculum specialists.

\subsection{Teacher Self-reflections on Learning and Practice}

On post-workshop surveys, teachers responded that the most helpful aspects of the workshops were the content presented by scientists and the hands-on activities such as water testing, oyster dissections and setting up a classroom oyster tank. Field training days and River Project workshops were also cited as highly useful for preparing to teach the BOP-CCERS curriculum. Teachers agreed with the statement, "I feel more prepared to teach the content and support students' learning of BOP-CCERS curriculum and field science practices." These responses suggest success in recruiting scientists who can share their research with teachers and connect both content and practices that teachers can utilize in implementing the BOP-CCERS curriculum. Respondents felt that the scientist presentations prepared them the most to teach their students about the New York Harbor, oyster restoration, and ecology. Lesson review with BOP educators was found to be helpful in preparing teachers to support their students' use of the digital platform. Teachers reported they received the least preparation from the

program on the use of the digital platform, so they were less inclined to use it. It is to be noted that the digital platform underwent continuous revision over the course of the three program cohorts. Overall, teachers responded most favorably to increasing their content knowledge of marine biology while activities on the use of the digital platform to collect and analyze data were the least impactful.

\subsection{Teacher Reflections on Student Learning}

Teachers reported that the BOP-CCERS program prepared them to support student learning of the program content and scientific research activities. They also indicated that students' awareness of STEM careers and stewardship of the New York harbor were heightened as a result of their field research experiences. One teacher commented, "I have students design and implement a lot of their own coastal field studies. I also have access to equipment/supplies to help gather quantifiable data on things like water quality." Another summarized it best as, "letting students strategize, plan, and run the expeditions and brainstorming solutions to problems in the field."

The inquiry-based experiential learning experiences modelled and experienced by teachers during the professional development sessions have profound impact on student learning in the classroom. Instead of learning solely by textbook, lectures or online resources, classrooms participating in the BOP-CCERS program provide opportunities for New York City public school students to learn about oyster biology, New York Harbor history and local ecology. In addition, experiential learning develops skills in collaboration, design of scientific investigations, and data collection using a digital database shared across schools in the BOP-CCERS program.

\subsection{Teacher Opinions on Continuing Implementation beyond Fellowship}

A majority of teachers reported that they continued using activities in the BOP-CCERS curriculum in their classroom after their fellowship ended. The classroom lessons and oyster restoration station field expeditions were cited as the most frequently used activities because they provided opportunities for student participation in hands-on field science. Teachers expressed that student interest was another reason why they continued to use the curriculum. Finally, by providing a place based real-world learning experience, students gain a greater sense of social responsibility in addition to learning content and developing skills. As summarized by one educator, "It's extremely important to the community 
of Coney Island to gain both an awareness of the environmental conditions of where they live and that they have both the right and the ability/power to affect positive change in their own environment." Learning experiences offered by the BOP-CCERS program models for inner city public school students the scientific research process and sparks a sense of social responsibility and personal interest in understanding and restoring their local natural environment.

\section{Discussion}

The BOP-CCERS professional development activities allowed inner city public school teachers to examine both content understanding and pedagogy through authentic experiences which resulted in greater effectiveness of educators involved in teaching an authentic STEM-C curriculum. In addition, teachers had a supporting network of peer educators, veteran teachers, scientists and other STEM professionals to troubleshoot questions related to content knowledge, lesson planning, setting up a classroom oyster tank, and organizing field experiences to collect data and monitor oyster growth with students. Teachers responded most positively to workshops that included hands-on activities, specifically the oyster restoration station trainings, classroom oyster tank setups and activities with scientists. These workshops provided inspiration for teachers' lessons and modelled best-practices for inquiry based, experiential learning through real-world investigations of a local ecological problem. Professional development sessions and BOP-CCERS workshops provide opportunities to model different ways teachers can integrate the BOP-CCERS platform into the classroom. The use of the platform by students is one way students could see themselves as contributing to real scientific research and increase their interest in science careers.

\section{Conclusion/Suggestions}

The BOP-CCERS program is a work in progress. Some suggestions for program improvement include:

- Providing recommended readings or websites to prepare teachers prior to the workshops.

- Posting materials after workshops allows teachers the ability to review content at their own pace.

- Further integrate the use of digital platform for data collection, data analysis and evaluation of the impacts of the BOP-CCERS project in New York Harbor.

- More support in developing inquiry-based teaching and learning practices.

The BOP-CCERS program continues to evolve with additional hands-on lessons, new iterations of the digital platform, and additional partnerships with local organizations and scientists. These program improvements are in alignment with the Next Generation Science Standards and provide a real-world context for students to learn STEM content and develop core skills necessary for a career in the STEM fields and to be competitive in the future workforce.

A major goal for the pedagogical aspects to the BOP-CCERS program is to create a sustainable model of experiential learning for teacher preparation and student engagement, which will have positive impacts on student dispositions toward science and consequently on their overall achievement in the science classroom. Students who engage in real-world science are more likely to see the relevance of science and see themselves as student scientists. Authentic learning experiences combined with stewardship and the integration of technology engages and motivates students to see the practical applications of STEM and to further pursue the STEM field as a career pathway.

\section{References}

Birney, L., \& Cronin, J. J. (2018). Environmental habitat restoration and inquiry-based learning with New York City public schools - an urban model in STEM education. Journal of Environmental Studies and Sciences, 9(3), 322-326. https://doi.org/10.1007/s13412-018-0530-5

Birney, L. B., Kong, J., Evans, B. R., Danker, M., \& Grieser, K. (2017). Microteaching: An introspective case study with middle school teachers in New York City public schools. Journal of Curriculum and Teaching, 6(2), 1-5. https://doi.org/10.5430/jct.v7n2p20

Birney, L. B., Kong, J., Evans, B. R., Persaud, A., \& Danker, M. (2018). Teachers mentoring teachers in the Billion Oyster Project and Curriculum and Community Enterprise for the Restoration of New York Harbor with New York City public schools (BOP-CCERS) fellowship. Journal of Curriculum and Teaching, 7(2), 20-26. https://doi.org/10.5430/jct.v7n2p20 
Birney, L., McNamara, D., Evans, B. R., Woods, N., \& Hill, J. (2019). The Curriculum and Community Enterprise for Restoration Science Partnership model. Journal of Curriculum and Teaching, 8(2), 1-10. https://doi.org/10.5430/jct.v8n2p1

Birney, L., McNamara, D., Sanders, C., Luintel, H., \& Penman, J. (2018). Curriculum and Community Enterprise for Restoration Sciences: The Expansion and Future of the Model. International Research in Higher Education, 3(4), 1-11. https://doi.org/10.5430/irhe.v3n4p1

Cobb, P. (1994). Where is the mind? Constructivist and sociocultural perspectives on mathematical development. Educational Researcher, 23(7), 13-20. https://doi.org/10.3102/0013189X023007013

Cobb, P., \& Yackel, E. (1996). Constructivist, emergent, and sociocultural perspectives in the context of

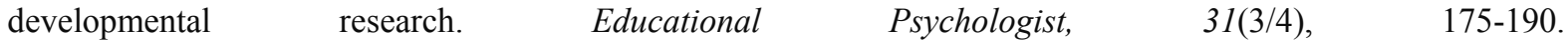
https://doi.org/10.1080/00461520.1996.9653265

Elliot, L. (2016). Experiential learning informs classroom instruction: Teaching environmental conservation in a middle school Spanish classroom. Excellence in Education Journal, 5(1), 24-52.

Fisher, N., Gerdes, K., Logue, T., Smith, L., \& Zimmerman, I. (1998). Improving students' knowledge and attitudes of science through the use of hands-on activities (Master's thesis). Saint Xavier University, Chicago, IL. Retrieved from https://eric.ed.gov/?id=ED436352

Gunter, G. A., \& Reeves, J. L. (2017). Online professional development embedded with mobile learning: An examination of teachers' attitudes, engagement and dispositions. British Journal of Educational Technology, 48(6), 1305-1317. https://doi.org/10.1111/bjet.12490

Ho, V. T., Nakamori, Y., Ho, T. B., \& Lim, C. P. (2016). Blended learning models on hands-on approach for in-service secondary school teachers: Combination of E-learning and face-to-face discussion. Education and Information Technologies, 21(1), 185-208. https://doi.org/10.1007/s10639-014-9315-y

Hollis, F. H., \& Fulya, E. (2016). Implementation of real-world experiential learning in a food science course using a food industry-integrated approach. Journal of Food Science Education, 15(4), 109-119. https://doi.org/10.1111/1541-4329.12092

Janis, S., Birney, L. B., \& Newton, R. (2016). Billion Oyster Project: Linking public school teaching and learning to ecological restoration of New York Harbor using innovative applications of environmental and digital technologies. International Journal of Digital Content Technology and its Application, 10(1), 1-14.

Kafyuililo, A. C. (2010). Practical use of ICT in science and mathematics teachers' training at Dar es Salaam University College of Education: An analysis of prospective teachers' technological pedagogical content knowledge (Master's thesis). Dar es Salaam University, Dar es Salaam, Tanzania. Retrieved from https://eric.ed.gov/?id=ED524251

Khaled, A., Gulikers, J. T. M., Biemans, H. J. A., \& Mulder, M. (2016). Occurrences and quality of teacher and student strategies for self-regulated learning in hands-on simulations. Studies in Continuing Education, 38(1), 101-121. https://doi.org/10.1080/0158037X.2015.1040751

Martin, F., \& Bolliger, D. U. (2018). Engagement Matters: Student Perceptions on the Importance of Engagement Strategies in the Online Learning Environment. Online Learning, 22(1), 205-222.

Stofer, K. A. (2017). Tools for using citizen science in environmental, agricultural, and natural resources extension programs. Journal of Extension, 55(2), 1-4.

Vygotsky, L. S. (1987). Thinking and speech. In R. W. Rieber \& A. S. Carton (Eds.), The collected works of Vygotsky, L. S. (Vol. 1): Problems of general psychology, 39-285. New York, NY: Plenum.

Note

Note 1. The 5 E's, Enhancing Education (2019). Retrieved from http://enhancinged.wgbh.org/research/eeeee.html 